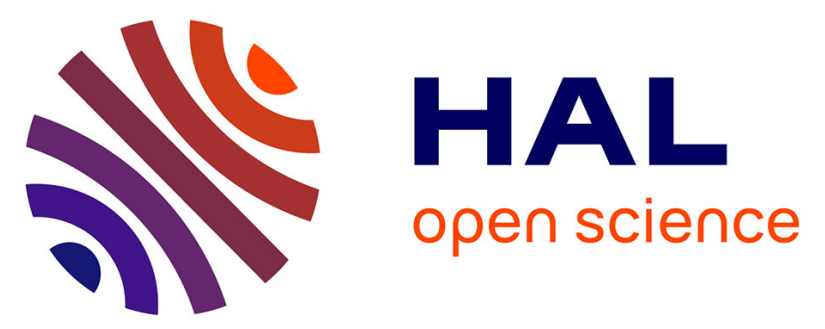

\title{
The Influence of In Situ Polymerized Epoxidized A/F Bisphenol-Chitosan on Features of Oilwell Cement Slurry-Molecular-Level Analysis and Long-Term Interaction of API Fracturing Fluid
}

Eunice F. S. Vieira, Pablo F. Lima, Ivory M. G. Dos Santos, Antonio S.

Mangrich, Amanda A. De Franca, Gwenn Le Saout, Antonio R. Cestari

\section{To cite this version:}

Eunice F. S. Vieira, Pablo F. Lima, Ivory M. G. Dos Santos, Antonio S. Mangrich, Amanda A. De Franca, et al.. The Influence of In Situ Polymerized Epoxidized A/F Bisphenol-Chitosan on Features of Oilwell Cement Slurry-Molecular-Level Analysis and Long-Term Interaction of API Fracturing Fluid. Journal of Applied Polymer Science, 2014, 131 (22), 10.1002/app.41044 . hal-02914355

\section{HAL Id: hal-02914355 \\ https://hal.science/hal-02914355}

Submitted on 3 Jun 2021

HAL is a multi-disciplinary open access archive for the deposit and dissemination of scientific research documents, whether they are published or not. The documents may come from teaching and research institutions in France or abroad, or from public or private research centers.
L'archive ouverte pluridisciplinaire HAL, est destinée au dépôt et à la diffusion de documents scientifiques de niveau recherche, publiés ou non, émanant des établissements d'enseignement et de recherche français ou étrangers, des laboratoires publics ou privés. 


\title{
The Influence of In Situ Polymerized Epoxidized A/F Bisphenol-Chitosan on Features of Oilwell Cement Slurry-Molecular-Level Analysis and Long-Term Interaction of API Fracturing Fluid
}

\author{
Eunice F. S. Vieira, ${ }^{1}$ Pablo F. Lima, ${ }^{1}$ Ivory M. G. dos Santos ${ }_{1}{ }^{1}$ Antonio S. Mangrich ${ }^{2,3}$ \\ Amanda A. de França, ${ }^{2}$ Gwenn Le Saoût, ${ }^{4}$ Antonio R. Cestari ${ }^{1}$ \\ ${ }^{1}$ Department of Chemistry/CCET, Laboratory of Materials and Calorimetry, Federal University of Sergipe, CEP 49100-000, \\ São Cristóvão, Sergipe, Brazil \\ ${ }^{2}$ Department of Chemistry, Federal University of Paraná, CEP 81531-990, Curitiba, Brazil \\ ${ }^{3}$ National Institute of Science and Technology-Energy and Environment E\&A, Salvador, Bahia, Brazil \\ 4École des Mines d'Alès (EMA), Centre des Matériaux des Mines d'Alès (C2MA) 6, avenue de Clavières 30319 Alès Cedex, France \\ Correspondence to: A. R. Cestari (E-mail: arcestari@gmail.com)
}

\begin{abstract}
A novel oilwell cement slurry was prepared with in situ polymerized epoxidized A/F bisphenol-chitosan and characterized by ${ }^{29} \mathrm{Si} \mathrm{NMR}$ and EPR spectroscopy. The hydrated and cured cement slurry evidenced the presence of unreacted clinker phases identified by the presence of orthosilicate groups along with the presence of hydration products identified by short linear polymeric silicate units typical of calcium silicate hydrate $(\mathrm{C}-\mathrm{S}-\mathrm{H})$. Two main $\mathrm{Fe}^{3+}$ domains and $\mathrm{Mn}^{2+}$-related hyperfine sextets were detected by EPR spectroscopy. After long-term contact with an API acidizing fluid, the features of the ${ }^{29} \mathrm{Si}$ NMR and EPR spectra did not change appreciably. The kinetics of overall solids dissolution upon contact with the hot acidizing fluid was modeled with the AvramiErofe'ev equation. The kinetic parameters are not very sensitive to changes of temperature. The values of the Avrami exponent suggest that diffusion-controlled processes without chemical reactions govern the overall rate of interaction processes or are partially involved in it. The results indicate that the A/F bisphenol-chitosan polymeric network can improve significantly the chemical stability of cement slurries in the presence of acidizing fluids and may be a good option for oil and gas industry.
\end{abstract}

KEYWORDS: biopolymers; kinetics; oil well cement slurries; solid-state characterization

\section{INTRODUCTION}

The accidents in oil and gas industry have been a matter of extreme concern around the world. The investigations of the Gulf of Mexico accident in 2010 have pointed out that the cement slurry used to seal some parts of an oil well did not meet the oil well industry standards. ${ }^{1}$ In fact, oil well cementing jobs have low tolerance to errors, and engineered materials have been help to develop procedures enabling safe and long-term performance of oil and gas wells. ${ }^{2}$

The scope of well cementing is to provide an adequate bond between the casing and the rock formation, to seal off the formation and to protect the pipe. The cement slurry is used to perform specific functions, strengthening and making impermeable certain well strata, blocking oil, gas, or water flows or the like. ${ }^{2,3}$ Advanced cementitious materials have been developed to have chemical stability and ensure long-term well durability. ${ }^{2}$
Poor cementing can lead to gas migration and excessive production of water-based fluids (produced water). ${ }^{2,3}$ In addition, failure to achieve good zonal isolation may lead to production rates lower than expected and/or environmental pollution problems.

The productivity of a given well may be impaired either by the natural characteristics of the reservoir rock and fluids or by damage resulting from drilling, completion, or production operations. Acid fracturing is a routine technique in oil and gas industry and has been a solution of many wells with problems of impaired production. This technique consists in the injection of an acidic fluid at a rate higher than the reservoir matrix could accept leading to the cracking of the rock. The majority of acidizing treatments carried out utilizes hydrochloric acid-based hot fluids. ${ }^{4}$ To achieve deeper and safer penetration in acid fracturing, it is often desirable to retard or avoid the contact of the acidic fluid with the 
hardened cement slurry. However, acid fracturing operations remain as a major concern to oil and gas industries around the world. Some oil wells can present zonal intercommunication problems, due to long-term reactions between the hardened cement slurry in the annulus and the acidic fluid. ${ }^{5}$ The major problem is the development of wormholes in the fracture interfaces. In many cases of acidic attack at hardened cement interfaces, the chemical reaction results in the formation of soluble calcium salts, which may be leached away by the aqueous solution. The $\mathrm{pH}$ value of the pore solution in the hardened slurry is also decreased, contributing to deteriorate such cement-based structures permanently. Some reviews have been published which describe important experimental factors affecting chemical attack on cement bodies. ${ }^{6-10}$ However, from a practical viewpoint, the rate of the attack has been considered of utmost importance to evaluate the long-term use of a given cement slurry composition in oil well field. ${ }^{9}$

Adequate long-term performances of oil well cement slurries are reached by using specific materials such as fly ash, fibers, and waterproofing agents. ${ }^{6}$ Some polymers, such as polyvinyl chloride, polyvinylacetate, polyacrylics, styrene butadiene copolymers, and epoxy resins are also used in oil well industry. ${ }^{11,12}$ For oil well applications, polymers have been considered materials of excellent performances. Polymer/cement composites are known to have higher tensile strength, deformability, adhesion, waterproofness and durability than conventional cement-based materials. ${ }^{13}$ Besides, adding a given polymer is a way to lighten slurries without impairing chemical, mechanical, and durability properties. ${ }^{12,13}$ Although the consistency of the mortars is often reduced in the presence of water-soluble polymers, the easiness to apply the fresh mixtures is markedly improved, because of the plasticizing, lubricating, and air-entraining effects of the polymers. ${ }^{12}$ All these reasons make polymer/cement composites interesting materials for oil well cementing. In this way, polymeric systems consisting of epoxy-type resins/diamines have been shown to be very promising for using in cement formulations. ${ }^{14}$

In oil well industry, one of the critical factors governing the achievement of an effective polymeric system is good adhesion at the interface polymer/hydrated cement. Some epoxidized bisphenol resins have been used in cement-based materials, due to their excellent adhesion properties in relation to other polymeric systems. ${ }^{12-14}$ This type of resin is obtained from the reaction between bisphenols and epichlorohydrin, where the number of epoxidized oxirane groups formed determines the end-use applications of such polymeric material. ${ }^{15}$ The curing of such resin occurs in bi-molecular through the opening oxirane rings of the epoxy component with specific molecules (hardeners), typically diamines. ${ }^{15}$ The presence of highly polar aliphatic hydroxyl and ether groups in bisphenol chains can serve as sites for the formation of strong interactions between bisphenol polymers and cement. ${ }^{11-14}$

Recently, our research group has prepared and evaluated oil well cement slurries with type-A epoxy resin and chitosan. ${ }^{16}$ The active primary amino groups of chitosan provided sites for formation of stable polymerized epoxidized bisphenols networks, employing mild reaction conditions in polyaddition reactions. However, it was noted that diffusion of acidic species into that slurry increases when temperature increases. This was observed to cause intense chemical degradation of such cement slurry and may avoid the use of such cement slurry in longterm applications in oil/gas industry, mainly those at high temperatures. In order to overcome this undesirable feature of type-A epoxy resin-based cement slurry, other epoxy resins can be evaluated such as type A/F epoxidized bisphenol resin, which according to the epoxy resin supplier technical information, has higher amounts of epoxidized groups in its chemical structure. Therefore, the combined use of such type A/F resin and a chitosan sample with a high deacetylation degree (typically higher than $80 \%)^{17}$ is supposed to form high amounts of epoxy/chitosan-based crosslinked-type groups in cement slurries. This polymeric system could provide better features in cement-based formulations for long-term uses, in relation to the previously evaluated type-A epoxy-chitosan polymeric system, even in tests performed at high temperatures. However, as far as we know, little is known regarding the molecular-level features of type A/F bisphenol resin/chitosan-modified oil well cement slurry, as well as its kinetic performance in relation to temperature, after long-time contact with the aggressive environments of oil wells.

It is widely recognized that the microstructural features of hardened cement slurries determine if a given cement slurry can be used in long-term applications in oil well field. Traditional characterization techniques, such as FTIR and XRD cannot provide the required information with sufficient accuracy since many cement-based materials have low crystallinity after exposition to the aggressive environment of oil wells. ${ }^{18}$ However, molecularlevel characteristics of cement-based materials can be provided by nuclear magnetic resonance spectroscopy (NMR) of ${ }^{29} \mathrm{Si}$. The solid-state ${ }^{29} \mathrm{Si}$ chemical shift reflects the local environment of the silicate tetrahedra, and in particular, their connectivity and the presence of Al substitutions. ${ }^{18}$ Therefore, solid-state ${ }^{29} \mathrm{Si}$ NMR can provide relevant structural information about the nature of the anhydrous and hydrated phases present in cement slurries.

On the other hand, the presence of $\mathrm{Fe}^{3+}, \mathrm{Mn}^{2+}$, and some free radicals, such as $\mathrm{O}^{\circ}$ and $\mathrm{O}_{2}{ }^{-}$enables the utilization of such components as spin labels for evaluating many specific structural features in cement-based materials using electron paramagnetic resonance (EPR). ${ }^{19}$ Because of its detection principle, EPR is a powerful tool for investigating the structures, the locations and dispersion of specific sites in solid samples as well as their features in several chemical environments. ${ }^{20}$

In this work, we prepared a new cement slurry modified with type A/F bisphenol resin/chitosan. For comparative purposes, a standard cement/water slurry (without the epoxy resin and chitosan) was also prepared and evaluated. Solid-state ${ }^{29} \mathrm{Si}$ NMR and EPR spectroscopy were used to describe the molecular-level features of the cement slurries before and after long-term contact with an API fluid used in routine oil well fracturing procedures. A kinetic study was performed to evaluate the role of temperature on the diffusion of the fluid into the new cement slurry. 


\section{EXPERIMENTAL}

\section{Materials and Reagents}

Class G oil well powder cement of 200-325 mesh, silica powder of 150-300 mesh (particles diameter) and API acidizing fluid $(\mathrm{HCl} 15 \%(\mathrm{v} / \mathrm{v})$ and sulfonate surfactant-based, $0.5 \%(\mathrm{v} / \mathrm{v}))$ were used, all from Schumberger-Petroleum Services (Nossa Senhora do Socorro/SE, Brazil). The A/F bisphenol solution was manipulated according to the technical specifications of the supplier (The Huntsman Co Special Resins, São Paulo, Brazil). According to supplier technical information, the chemical structures of type A/F epoxy resin present higher branched epoxidized oxirane rings (from 4.0 to 6.0 ) in its chemical structure in relation to chemical structure of type A epoxy resin (from 1.0 to 3.0 ). The chitosan powder (84\% of deacetylation degree) was from C.E. Roeper GmbH, Hamburg (Germany).

\section{Preparation of the Cement Slurries}

The slurries were prepared targeting an average density of $1.75 \pm 0.15 \mathrm{~g} \mathrm{~cm}^{-3}$ after hydration and cure, according to technical specifications of the American Petroleum Institute (API) practices for class $G$ cements. ${ }^{2,3,16}$ In order to provide an efficient and stable reticulated polymeric system, a preparation procedure was employed as described previously with a few modifications. ${ }^{16}$ The polymer-modified slurry was prepared using $200 \mathrm{~g}$ of cement, $70 \mathrm{~g}$ of silica and $100 \mathrm{~mL}$ of water $(w / c=0.50$ and $s / c=0.35)$, and an epoxidized bisphenol A/F-chitosan aqueous suspension (5 wt \% in relation to the cement mass. The masses of epoxy resin $(5.0 \mathrm{~g})$ and chitosan $(5.0 \mathrm{~g})$ were calculated in order to supply a ratio of these components of $1: 1$ ), as reported previously. ${ }^{16}$. All components were mixed at $12,000 \mathrm{rpm}$ for $50 \mathrm{~s}$. For comparative purposes, a cement/silica slurry (without the epoxy resin and chitosan, $[w / c=0.50)]$ was also prepared using the same mixing procedure.

The cement slurries were cast into individual API cubic molds with $5.08 \mathrm{~cm}$ sides and initially cured in the presence of water vapor for $1 \mathrm{~h}$, in a desiccator containing $200 \mathrm{~mL}$ of distilled water. After this time period, the cement bodies were removed from the molds and cured directly in distilled water in a temperature-controlled bath for 30 days at $25^{\circ} \mathrm{C}$. Physical damages, dilution of cement or diffusion of chitosan were not detected during the entire period of hydration of the slurries. For simplicity, the slurries are hereafter denominated as slurry-1 (cement/silica) and slurry-2 (cement/silica/in situ polymerized A/F bisphenol-chitosan net).

Kinetics of Oil Well Fracturing Fluid with the Cement Slurry The kinetic contact experiments of the hardened cement samples with the fracturing fluid were performed in isothermal batch conditions, from 25 to $60^{\circ} \mathrm{C}$. In a typical experiment, a cured cubic sample was put in contact with $400 \mathrm{~mL}$ of API fracturing fluid in a sealed glass container at a selected temperature (precision of $\pm 0.1^{\circ} \mathrm{C}$ ). ${ }^{16,21}$ For simplicity, the interaction amounts of the API fluid with slurry-2 were determined in terms of the acidity of the API fluid. Therefore, at predetermined time intervals, aliquots of $3 \mathrm{~mL}$ of the solution were withdrawn and the acidic concentration $\left[\mathrm{H}^{+}\right]$of the fluid was determined at room temperature using a $\mathrm{pH}$-meter.
The extent of interaction of the API fluid with the cementbased materials was calculated using the expression ${ }^{16,21}$ :

$$
Q_{t}=\frac{\left(C_{i}-C_{t}\right) V}{m}
$$

where $Q_{t}$ is the fixed quantity of API fluid per gram of material in mol g ${ }^{-1}, C_{i}$ is the initial $\left[\mathrm{H}^{+}\right]$concentration of the API fluid in $\mathrm{mol} \mathrm{L}^{-1}, C_{t}$ is the $\left[\mathrm{H}^{+}\right]$concentration of API fluid at a given time $t$ in $\mathrm{mol} \mathrm{L}^{-1}, V$ is the volume of the API solution in $\mathrm{L}$ and $m$ is the mass of the material in grams.

For the characterization of the solid samples, according to API regulations for oil well cement acidizing, a contact time of 400 min was chosen to evaluate the samples after contact with the fracturing fluid. The samples were washed with distilled water, powdered, sieved (250-300 mesh), and dried at $50^{\circ} \mathrm{C}$ for $4 \mathrm{~h}$ before characterization.

\section{Characterization of the Cement Samples}

The ${ }^{29} \mathrm{Si}$ MAS NMR spectra were recorded on a Bruker Avance 400 NMR spectrometer (field strength of $9.4 \mathrm{~T}$ ) at $79.49 \mathrm{MHz}$ applying $5 \mathrm{kHz}$ spinning rates on a $7.5 \mathrm{~mm}$ CP MAS probe using $\mathrm{ZrO}_{2}$ rotors. Single- pulse experiments were carried out by applying $90^{\circ}$ pulses with ${ }^{1} \mathrm{H}$ decoupling and recycle delays of $10 \mathrm{~s}$. The ${ }^{29} \mathrm{Si}$ chemical shift was referenced externally relative to tetramethylsilane (TMS) at $0.0 \mathrm{ppm}$. The recycle delay of $10 \mathrm{~s}$ was used in order to comply with the relaxation times of the anhydrous cement and $\mathrm{C}-\mathrm{S}-\mathrm{H}$. However this relaxation time is too short for quartz and silica gel that may have an extremely long relaxation delay. The ${ }^{29} \mathrm{Si}$ isotropic chemical shifts were resolved and measured to $\pm 0.1 \mathrm{ppm} .^{22,23}$

The EPR spectra ( $\mathrm{X}$ band, first derivative mode, modulation frequency $100 \mathrm{kHz}$ ) of the powdered samples were recorded on a Bruker EMX spectrometer at room temperature $\left(25^{\circ} \mathrm{C}\right)$. The EPR parameter values were obtained by treating and simulating the experimental spectra using the Windows software programs Win-EPR ${ }^{\circledR}$ and the Weak Pitch Bruker pattern. ${ }^{24}$

The DRX diffractograms of the materials were obtained in a Shimadzu diffractometer in the $2 \theta$ range from 5 to $80^{\circ}$ (accumulation rate of $0.02^{\circ} \mathrm{min}^{-1}$ ), using $\mathrm{Cu} \mathrm{K} \alpha$ radiation $(\lambda=0.15419 \mathrm{~nm}){ }^{16}$

\section{RESULTS AND DISCUSSION}

\section{Preliminary Information}

Some preliminary information on the chemistry of both cement and polymer-modified oil well cement slurries is useful to properly understand the results of the present work.

Portland cement is produced by firing limestone and some clays at about $1500^{\circ} \mathrm{C}$ to produce a "clinker," with a final addition of about 2-6 wt \% of gypsum. In general, Portland cements contain 50-75 wt \% $\mathrm{Ca}_{3} \mathrm{SiO}_{5}$ (tricalcium silicate, “alite," typically denoted as $\mathrm{C}_{3} \mathrm{~S}$, where the terms " $\mathrm{C}$ " and " $\mathrm{S}$ " stand for $\mathrm{CaO}$ and $\mathrm{SiO}_{2}$, respectively), 5-27 wt $\% \mathrm{Ca}_{2} \mathrm{SiO}_{4}$ (dicalcium silicate, "belite," $\mathrm{C}_{2} \mathrm{~S}$ ), 1-18 wt \% $\mathrm{Ca}_{3} \mathrm{Al}_{2} \mathrm{O}_{6}$, (tricalcium aluminate, $\left.\mathrm{C}_{3} \mathrm{~A}, \mathrm{~A}=\mathrm{Al}_{2} \mathrm{O}_{3}\right)$ and $0-18$ wt $\%$ aluminoferrite $\left(\mathrm{Ca}_{2}\left(\mathrm{Al}_{\mathrm{x}} \mathrm{Fe}_{1}\right.\right.$ $\left.\left.{ }_{\mathrm{x}}\right)_{2} \mathrm{O}_{5}, 0<x<0.75, \mathrm{C}_{4} \mathrm{AF}, \mathrm{F}=\mathrm{Fe}_{2} \mathrm{O}_{3}\right) . \mathrm{C}_{3} \mathrm{~S}$ is responsible for the early setting of cement. $\mathrm{C}_{2} \mathrm{~S}$ reacts with water slowly and is responsible for the later development of mechanical strength. 
Cement hydration can be expressed in a simple form as follows ${ }^{2,3,22}$ :

$$
\begin{aligned}
3 \mathrm{CaO} \cdot \mathrm{SiO}_{2}+x \mathrm{H}_{2} \mathrm{O} \longrightarrow & y \mathrm{CaO} \cdot \mathrm{SiO}_{2} \cdot(y-(3-x)) \mathrm{H}_{2} \mathrm{O} \\
& +(3-y) \mathrm{Ca}(\mathrm{OH})_{2}
\end{aligned}
$$

$\mathrm{C}_{3} \mathrm{~S}$ hydration is a dissolution/precipitation process, and that what is shown in eq. (1) is only the sum of several phenomena occurring during hydration. Calcium silicate hydrate $(\mathrm{C}-\mathrm{S}-\mathrm{H})$ is a nonstoichiometric material and the main component in hardened cement slurries. The stoichiometry of $\mathrm{C}-\mathrm{S}-\mathrm{H}$ is the result of the solution ionic composition, mainly due to the concentration of $\mathrm{Ca}^{2+}$ ions, but influenced also by $\mathrm{SO}_{4}{ }^{2-}$ and alkali ions. $\mathrm{C}-\mathrm{S}-\mathrm{H}$ is initially formed by dimeric silicate units, but it polymerizes after a few days to produce linear or branched pentamers or octamers units, collectively called polymers. Calcium hydroxide (portlandite, $\mathrm{CH}$ ) is also formed during the hydration period, mainly from the excess $\mathrm{Ca}^{2+}$ dissolved by $\mathrm{C}_{3} \mathrm{~S}$ with respect to the precipitating $\mathrm{C}-\mathrm{S}-\mathrm{H}$, and from the hydration of free lime if present, as follows ${ }^{2,3}$ :

$$
\mathrm{CaO}_{(\mathrm{s})}+\mathrm{H}_{2} \mathrm{O}_{(\mathrm{l})} \longrightarrow \mathrm{Ca}(\mathrm{OH})_{2(\mathrm{aq})}
$$

Silica powder is an important additive used in oil field industry, because silica can improve cohesiveness and compressive strength of hardened cement mixtures, and it avoids particle segregation as well. ${ }^{23,24}$ At $\mathrm{pH}$ values of $11.3-12.5$, some $\mathrm{Ca}^{2+}$ and $\mathrm{OH}^{-}$ions from $\mathrm{CH}$ react with silica to form additional $\mathrm{C}-\mathrm{S}-\mathrm{H}$ as shown in eq. (4). In general, the additional $\mathrm{C}-\mathrm{S}-\mathrm{H}$ phase is more resistant to attacks from the chemically aggressive environments of oil wells then $\mathrm{CH}$.

$$
\mathrm{SiO}_{2(\mathrm{~s})}+\mathrm{nCa}^{2+}{ }_{(\mathrm{aq})}+2 \mathrm{nOH}^{-}{ }_{(\mathrm{aq})} \longrightarrow \mathrm{nCaO} \cdot \mathrm{SiO}_{2} \cdot \mathrm{nH}_{2} \mathrm{O}
$$

where $n$ is a number related to the $\mathrm{CaO} / \mathrm{SiO}_{2}$ ratio.

Bisphenol cement mortars with hardeners have proved to have specific and better properties than the neat cement mortars. Specifically, higher functional epoxidized A/F bisphenols can react with linear polymers with amine groups, such as chitosan, providing in situ branched rigid thermosetting cement-polymer structures. ${ }^{16}$ As such the stoichiometry of $\mathrm{C}-\mathrm{S}-\mathrm{H}$ may be altered by the presence of the epoxy resin. Several mechanisms have been proposed to explain the epoxy/cement interaction, including mechanical interlocking involving pores, holes and crevices of the cement body, and electrostatic or adsorptive interaction of the polymer-modified cement environment. ${ }^{2,3,12}$ However, important structural features of polymer/C-S-H interactions have not fully understood.

The qualitative DRX analysis (details not shown) has provided results described elsewhere, which are typical for hydrated cement pastes. ${ }^{16}$ For slurry-1, the most prominent crystalline products and their respective interplanar distances $(d)$, determined by the Bragg equation ${ }^{2,3}$, were $\mathrm{CH}, \quad(2 \theta=18$, $d=0.490 \mathrm{~nm}$ and $34, d=262 \mathrm{~nm}$ ), tobermorite and ettringite $\left(2 \theta \sim 40^{\circ}, d=0.246 \mathrm{~nm}-50^{\circ}, d=0.182 \mathrm{~nm}\right)$, and mixtures of quartz, calcite and aragonite, $\left(2 \theta \sim 21^{\circ}, d=0.425 \mathrm{~nm}\right.$ and $28^{\circ}$, $d=0.311 \mathrm{~nm})$. For slurry-2, a very similar XRD profile has obtained. So, the XRD technique seems to be unable to comparatively analyze the materials of this work.
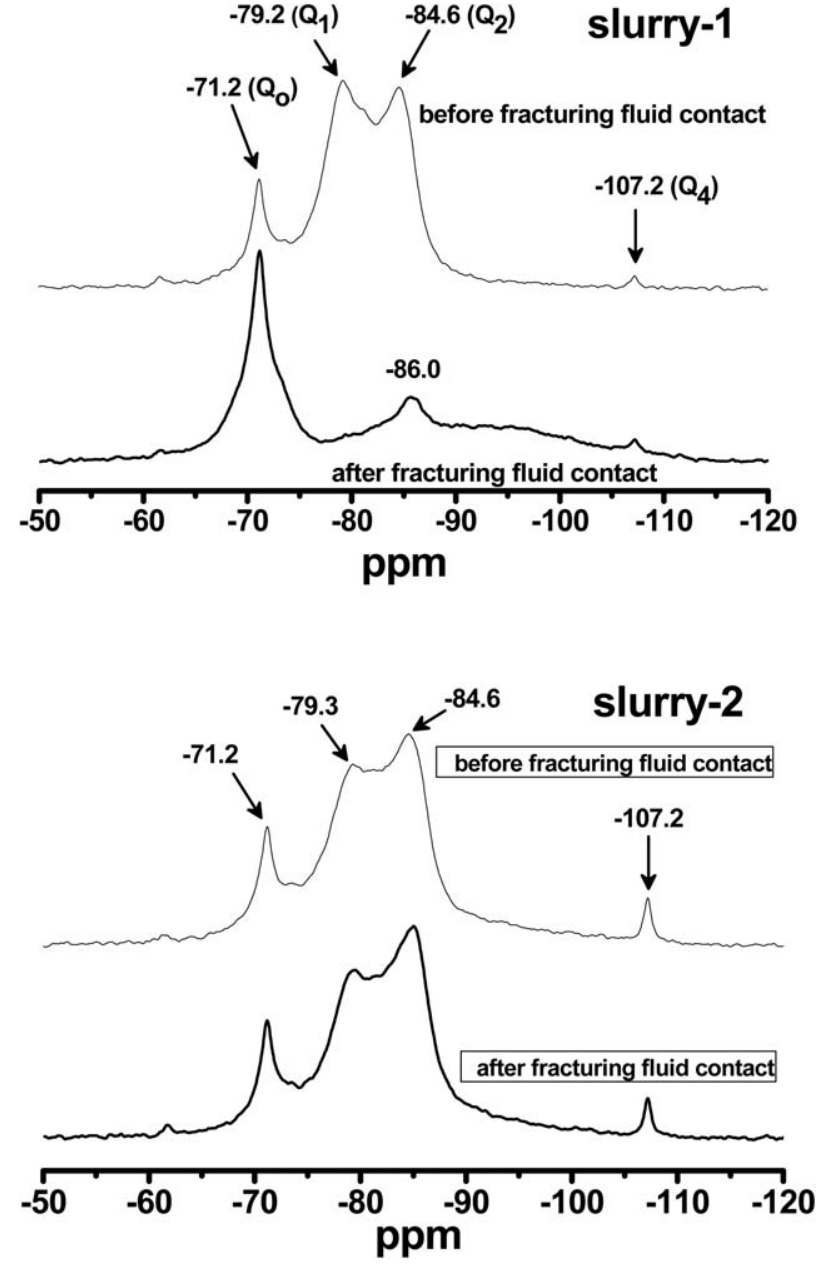

Figure $1 .{ }^{29} \mathrm{Si}$ MAS NMR spectra of slurry-1 and slurry-2, before and after long-term contact with API oil well hot acidizing fluid.

Characterization of the Cement Slurries by Solid-State ${ }^{29} \mathrm{Si}$ NMR In general, the range of ${ }^{29} \mathrm{Si}$ chemical shifts in silicates is located from -60 to $-120 \mathrm{ppm}$. In this work, the analysis of the observed ${ }^{29} \mathrm{Si}$ chemical shifts were performed using the $\mathrm{Q} n(m \mathrm{Al})$ classification, where one $\mathrm{Si}$ tetrahedron is connected to $n$ Si tetrahedra with $n$ varying from 0 to $4 ; m$ is the number of neighboring $\mathrm{AlO}_{4}$ tetrahedra. The important amount of $\mathrm{Fe}$ in oil well cement may degrade the NMR signal due to ${ }^{29} \mathrm{Si}-\mathrm{Fe}^{3+}$ unpaired electron dipolar couplings. However, Fe is mainly concentrated in the ferrite phase and $\mathrm{Fe}$ in Portland cement does not migrate through the pore solution on hydration, but remains in products formed in situ. ${ }^{25}$ Then, reasonable welldefined NMR spectra can be obtained from phases except ferrite and hydrated products formed in situ. ${ }^{25}$

The ${ }^{29} \mathrm{Si}$ NMR spectra of slurry-1 and slurry-2, before and after contact with hot fracturing fluid are shown in Figure 1. The spectra show near $-71 \mathrm{ppm}$ resonances from the $Q_{0}$ units of the anhydrous cement (alite and belite) ${ }^{25}$ which are still present after 1 month of hydration.

The broad resonance peaks with maxima at -79.2 and -84.6 ppm are due to polymeric end-chain tetrahedra $\left(Q_{1}\right)$ and middle nonbridging tetrahedra units $\left(Q_{2}\right)$ in polymer chains of 
C $-\mathrm{S}-\mathrm{H}$, respectively. This confirms that short chains of Sicentered tetrahedra are formed as the result of hydration. The relatively high $\mathrm{Ca} / \mathrm{Si}$ ratio (ca., 1.7-1.8) characteristic of $\mathrm{C}-\mathrm{S}-\mathrm{H}$ in Portland cement paste induces the formation of short disordered chains of silicate tetrahedra. ${ }^{25}$ This is consistent with the broad and overlapping ${ }^{29} \mathrm{Si}$ signals from the $Q_{1}$ and $Q_{2}$ species in Figure $1 .^{26,27}$ The peak for the $Q_{1}$ site is asymmetric and has a shoulder centered at about $-82.5 \mathrm{ppm}$, which has been assigned to $\mathrm{Q}_{2}(1 \mathrm{Al})$ species. ${ }^{4}$ The $Q_{3}$ peak, which is ascribed to branched cross-linked $\mathrm{C}-\mathrm{S}-\mathrm{H}$ structures, typically observed as shoulders or small peaks near about -90 ppm in many ${ }^{29} \mathrm{Si}$ NMR spectra, ${ }^{27}$ is not observed in pristine ${ }^{29} \mathrm{Si}$ NMR spectrum of slurry-1. The small broad peak of $Q_{4}$ type site centered at $-107.2 \mathrm{ppm}$ is characteristic of crystalline quartz, whereas other broad peaks from -98.0 to $-110 \mathrm{ppm}$, which are characteristic of amorphous $\mathrm{SiO}_{2}$, are not observed. This last evidence suggests that most of the silica was consumed during the slurry hydration, but we cannot exclude that the relaxation time of silica powder is too long and prevents its detection by solid-state ${ }^{29} \mathrm{Si} \mathrm{NMR}{ }^{25}$

After contact with API fracturing fluid, a decrease of the intensities of $Q_{1}$ and $Q_{2}$ peaks was observed and only one small $Q_{2}$ peak centered at $-86.0 \mathrm{ppm}$ appeared. These observations have been attributed to a systematic change of the $\mathrm{Ca} / \mathrm{Si}$ ratio due to a partial decalcification of some structural environments in $\mathrm{C}-\mathrm{S}-\mathrm{H}^{21}$ Indeed, from EDX measurements (details not shown), the average $\mathrm{Ca} / \mathrm{Si}$ ratio of slurry-1 decreased from about 1.55 to about 0.40 upon contact with the acid fracturing fluid. Typically, acidic fluids remove $\mathrm{CH}$ before $\mathrm{C}-\mathrm{S}-\mathrm{H}$ begins to decalcify. The dominant mechanism has been related to substitution or leaching of interlayer $\mathrm{Ca}$ of $\mathrm{C}-\mathrm{S}-\mathrm{H}$, which is balanced by the silicate anions of the bridging tetrahedra, leading to the formation of less crystalline $\mathrm{C}-\mathrm{S}-\mathrm{H}$ compounds. ${ }^{19,27}$ The process of acidic attack may result in the total decomposition of the hydration products, and silica, alumina and ferric hydrogels are the final products. Almost all hydration products of cement based materials, such as portlandite, tobermorite, ettringite and hydrogarnets have been noticed to be unresistant in acidic solutions. ${ }^{9}$

Interestingly, a low intensity broad peak centered at about -96 ppm is now observed, which may be due to some $Q_{3}$ units from dissolved $\mathrm{C}-\mathrm{S}-\mathrm{H}^{25}$ The peak of $\mathrm{Q}_{4}$ unit was found as in the pristine slurry-1 NMR spectrum, due probably to the relatively high chemical stability of quartz in hot aqueous acidic media. $^{28}$

For slurry-2 the same peaks as described in the ${ }^{29} \mathrm{Si}$ NMR spectrum of pristine slurry-1 are observed. However, the $Q_{2} / Q_{1}$ ratio is higher compared with pristine slurry-1. The interpretation of the features of $Q_{1}$ and $Q_{2}$ peaks of the ${ }^{29} \mathrm{Si}$ NMR spectra of slurry-2 is not easy and open to discussion. The $Q_{2} / Q_{1}$ ratio reflects the mean length of the silicate chain and increases as a result of the presence of the branched polymeric net in the slurry-2. Several organic polymer species can be involved in different kinds of interaction with $\mathrm{C}-\mathrm{S}-\mathrm{H}$ by intercalation, grafting at sites of some specific Si-tetrahedra or combinations of both. Many locations where there are missing bridging tetrahe- dra are considered as "nanostructural defects" and potential sites for polymer interactions. Some polymer molecules can also intercalate into the silicate interlayer spaces as well. ${ }^{29}$ Indeed, polymer organic moieties have been reported to be grafted on the edges of $\mathrm{C}-\mathrm{S}-\mathrm{H}$ chains leading to a greater number of $\mathrm{Q}_{2}$ units and hence to an increase of $Q_{2} / Q_{1}$ ratio. $^{30}$

In general, chemical shifts for $\mathrm{Si}$ occur in the following main cases: $-\mathrm{O}-\mathrm{Si}-\mathrm{O}-\mathrm{H} ;-\mathrm{O}-\mathrm{Si}-\mathrm{O}-\mathrm{Si}-$ and $-\mathrm{O}-\mathrm{Si}-\mathrm{O}-$ (organic polymeric net). ${ }^{18}$ The electrons of the atoms in the vicinity of silicate bonds can shield the Si nuclei resulting in detectable chemical shifts. However, it is reported that different silicate-polymer interactions may also result in similar chemical shifts. Therefore, the chemical shift of $\mathrm{Si}$ in the vicinity of a given organic polymer can mimic a $Q_{2}$ peak. ${ }^{18}$ This would also explain the increase in the $Q_{2} / Q_{1}$ ratio observed in the slurry-2 ${ }^{29} \mathrm{Si}$ NMR spectra.

It can be noted that the ${ }^{29} \mathrm{Si} \mathrm{NMR}$ spectra of slurry- 2 are more or less the same, before and after API fluid contact, suggesting that this slurry is largely unaffected by the acidic contact under the conditions described in this work. The access to the internal structure of $\mathrm{C}-\mathrm{S}-\mathrm{H}$ seems to be impeded by interaction of the polymeric phase with the cement structure. The absence of aqueous-phase diffusion of deleterious species (mainly $\mathrm{H}_{3} \mathrm{O}^{+}$ and $\mathrm{Cl}^{-}$) into the silicate structure of slurry-2 provides the blocking of silicate depolymerization reactions. This behavior could also be due to the elimination of specific defects at sites of some bridging Si-tetrahedra along the silicate chains in contact with the branched polymeric net. ${ }^{18,19}$ Therefore, the in situformed branched A/F bisphenol-chitosan polymeric net seems to have an excellent potential to mitigate the effects of deleterious processes occurring by the use of API fracturing fluids during routine acidizing procedures in oil and gas industry.

\section{Characterization of the Cement Slurries by EPR}

EPR spectroscopy offers information on the equilibrium structures of cement systems containing one or more unpaired electrons. Some metals such as iron, cobalt, and nickel are ferromagnetic and show intense EPR signals due to the parallel ordering of the electron spins. ${ }^{20}$ The $g$-value is an important parameter in identifying information about a paramagnetic center's electronic structure in a given specific symmetry. The $g$-values can be determined from the equation $g=h v / \beta B$, where $h$ is the Planck's constant, $v$ is the frequency, $\beta$ is the Bohr magneton, and $B$ is the field at which a specific resonance occurred. Figure 2 shows the first derivative mode EPR spectra in a magnetic field range of 5,000 $\mathrm{G}$ for slurry-1 and slurry-2, both before and after hot fluid contact. The EPR spectra of anhydrous class $G$ cement and powder silica used in the preparation of both cement slurries are shown in Figure 3.

The main absorption lines in the EPR spectra for all cement samples are due to the presence of different $\mathrm{Fe}^{3+}$ and $\mathrm{Mn}^{2+}$ ion domains. $^{31,32}$ Indeed, trace compounds associated with $\mathrm{Fe}^{3+}$ have been found in hydrated cement products. Previous analysis of oil well cement slurries by solid-state UV-vis spectroscopy have shown broad absorption bands centered at about 580 and $620 \mathrm{~nm}$, due to the presence of crystal field absorptions of $\mathrm{Fe}^{3+}$ 

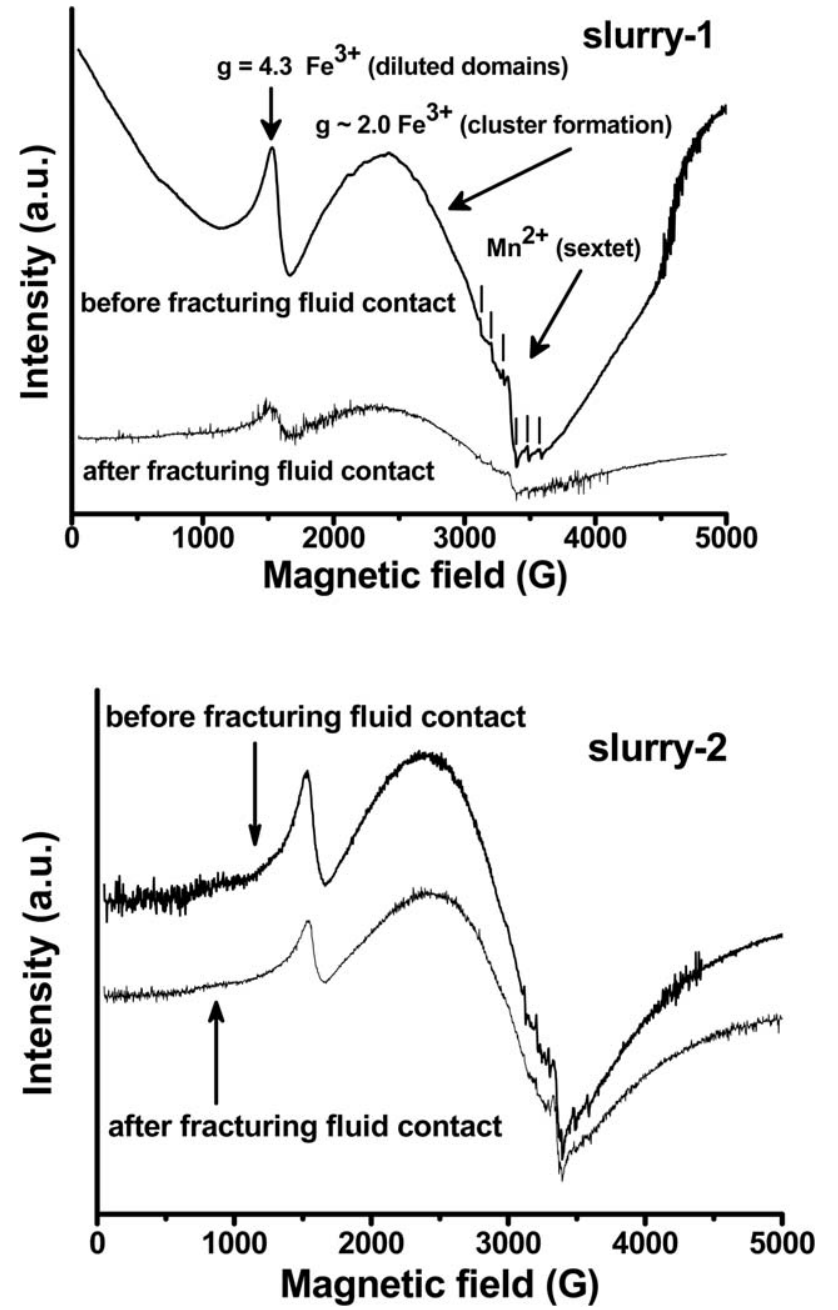

Figure 2. EPR spectra of slurry-1 and slurry-2, before and after long-term contact with API oil well hot acidizing fluid.

in octahedral coordination in hematite and ferrihydrite structures, respectively. ${ }^{16}$

In the EPR spectra, the first $\mathrm{Fe}^{3+}$ domains are called "diluted domains," located in magnetic field 1,500 G and attributed to

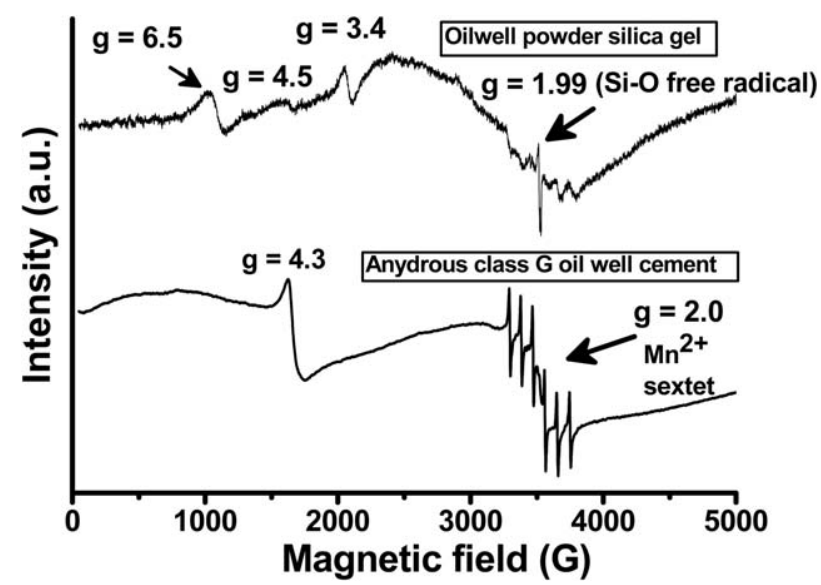

Figure 3. EPR spectra of oil well powder silica gel and anhydrous class G oil well cement. each $\mathrm{Fe}^{3+}$ species isolated from each other, corresponding to sites of rhombic $\mathrm{Fe}^{3+}$, typically in distorted tetrahedral and octahedral chemical environments, surrounded by four or six oxygen ligands from the hydrated cement structure. ${ }^{31}$ This suggests the absence of $\mathrm{Fe}-\mathrm{O}-\mathrm{Fe}$ interactions and the presence of a main single chemical environment. The other domains, characterized by having a much broadened peak from about 2,500 to $3,500 \mathrm{G}(g \sim 2.0)$, are referred to as a "concentrated or clustered domain," suggesting $\mathrm{Fe}-\mathrm{O}-\mathrm{Fe}$ interactions. During cement hydration, the resonance EPR lines due to $\mathrm{Fe}^{3+}$ species interactions becomes broader and distributed over a broad range of spectra. ${ }^{19}$ The concentrated domains have been attributed to spin-spin interactions among $\mathrm{Fe}^{3+}$ ions in silicate structures and are typically found in some nearly tetrahedral or octahedral $\mathrm{Fe}^{3+}$ ions in the crystalline field, due to the presence of oxides or oxy-hydroxides of $\mathrm{Fe}^{3+}$ alone or combined on the surface of the hydrated oil well cement particles. ${ }^{33}$

In almost all EPR spectra, the $\mathrm{Fe}^{3+}$ signal at $g \sim 2.0$ (about $3,100 \mathrm{G}$ ) is superimposed by a hyperfine splitting sextet due to the presence of a $\mathrm{Mn}^{2+}$ impurity, ${ }^{31,32}$ which is also found in the EPR spectrum of anhydrous class $G$ cement. It is believed that this kind of impurity is incorporated in some $\mathrm{Ca}^{2+}$ positions in the lattice of $\mathrm{CH}$ during the hydration of the cement slurries. ${ }^{19}$

For slurry-1, after API hot fluid contact, the intensities of all EPR lines decreased markedly and are weaker than in pristine slurry-1 EPR spectrum. It is also difficult to note the presence of the $\mathrm{Mn}^{2+}$ sextet in this case, due to the partial destruction of $\mathrm{C}-\mathrm{S}-\mathrm{H}$ and $\mathrm{CH}$. However, the $\mathrm{Fe}^{3+}$ signals can still be found, which suggests that some iron-containing species in the "diluted domains" were not fully removed by the contact with the hot API fluid, or that disrupted $\mathrm{Fe}^{3+}$ clusters increased the amount of $\mathrm{Fe}^{3+}$ in the diluted domains.

For slurry-2, the EPR spectra are more or less the same before and after hot API fluid contact. It has been postulated that highly branched bisphenol-based polymers act as adequate bonding agents between the different $\mathrm{C}-\mathrm{S}-\mathrm{H}$ and $\mathrm{CH}$ layers, increasing interparticle bonding. By "gluing" the crystal layers together, the crystalline microstructure of cement slurries can be strengthened. ${ }^{2,3}$

Kinetics of Fracturing Fluid Interaction

Many attempts have been made to formulate general mathematical expressions, which would be able to adequately describe the kinetics of interaction at solid/solution interfaces. ${ }^{33}$ This has led to expressions related to chemical reactions occurring on the surface or interaction sites found inside the pores of the solid phase occurring at the surface or at interaction sites inside the pores of the solid phase. The kinetic curves of API acidizing fluid interaction onto slurry-2 are presented in Figure 4. Unfortunately, the kinetic results using slurry-1 were nonreproducible, due probably to the partial destruction of this material after long-term API acidizing fluid contact.

Traditional pseudo first- and second-order kinetic models have been used to obtain parameters in several systems interacting at the solid/solution interface. ${ }^{34}$ Their main advantages are simplicity and ease of implementation without the use of advanced 

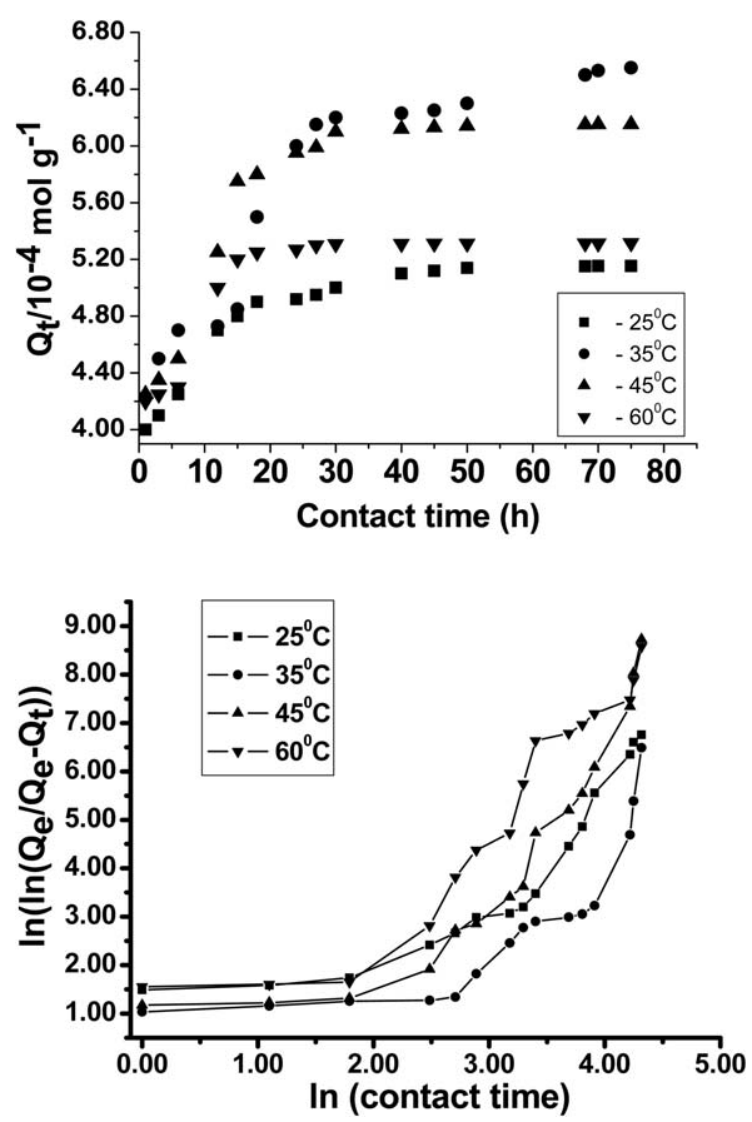

Figure 4. Kinetic plots of the interaction of acidizing API fluid on slurry2 in relation to temperature (higher part) and the kinetic order-related kinetic plots (lower part).

computational routines. However, the kinetic order of a given interaction reaction may not be an integer number ( 1 for the first-order and 2 for the second-order kinetic model). In these cases, the kinetic parameters do vary with time or the solid phase concentration $\left(Q_{t}\right)$ and the rate constants may not be invariable. Therefore, the real validity of the numeric values of the calculated kinetic parameters may be suspect or even invalid. In order to overcome all these inconveniences, a kinetic order-variable exponential equation was used in this work, as shown in eq. $(04)^{35}$ :

$$
Q_{t}=Q_{e}\left(1-\exp ^{-(k . t)^{a}}\right)
$$

where $k$ is the kinetic rate and $a$ is a constant related to the interaction mechanisms. The linearized form of this equation is:

Table I. Kinetic Parameters of Interaction of API Acidizing Fluid with Slurry-2 in Relation to Temperature

\begin{tabular}{llllll}
\hline & $\begin{array}{l}Q_{e} / 10^{-4} \\
\left(\mathrm{~mol} \mathrm{~g}^{-1}\right)\end{array}$ & $k\left(h^{-1}\right)$ & $a$ & $r^{2}$ & $X^{2} / 10^{-5}$ \\
\hline 25 & 5.15 & 0.70 & 0.480 & 0.989 & 0.93 \\
35 & 6.50 & 0.52 & 0.566 & 0.998 & 1.06 \\
45 & 6.10 & 0.50 & 0.521 & 0.967 & 0.97 \\
60 & 5.25 & 0.55 & 0.432 & 0.970 & 1.02 \\
\hline
\end{tabular}

$$
\ln \left(\ln \left(\frac{Q_{e}}{Q_{e}-Q_{t}}\right)\right)=a \ln k+a \ln t
$$

From the slopes and intersections values of the $\ln \left(\ln \left(Q_{e} / Q_{e}-Q_{t}\right)\right)$ $v s \ln t$ plots (Figure 4, lower part), the values of $a$ and $k$ can be calculated, respectively. Equations (5) and (6) were successfully used to describe the kinetic behavior of interactions occurring at solid/solution interfaces. ${ }^{36}$ This kinetic model was initially conceived for solid state reactions, to account for $3 \mathrm{D}$ growth of random distributed nuclei. Typically, to the exponent $a$ is attributed a physical meaning, but care shall be taken in the consideration of the different process to which the model is applied in the present context: a liquid/solid dissolution reaction. In this work, we determined the kinetic parameters $k$ and $a$ until about the first $20 \mathrm{~h}$ of contact, because they are numerically more appropriate to describe the kinetic features of the interaction between slurry2 and the API fracturing fluid. This probably has some influence on the lower significance of the longer-term kinetic data, extending after $20 \mathrm{~h}$ of contact, where diffusive processes may become predominant. In addition, the early stages of interaction phenomena occurring at cement/solution interfaces usually determine the long-term features of cement-based materials. ${ }^{2,3}$

In general, different models are often tested and the appropriate best-fit procedures are used to find the best model to describe experimental-simulated correlations. The linear least-squares method $\left(R^{2}\right)$, applied to the transformed kinetic data has been adopted for this purpose. However, $R^{2}$ is sensitive to extreme experimental data points of the correlations plots, resulting in misleading indication of the quality of a given fit. In this work, the fittings of the exponential kinetic model were done using chi-square $\left(\chi^{2}\right)$ analysis, according to eq. (6): ${ }^{36}$

$$
\chi^{2}=\sum \frac{\left(Q_{t, e}-Q_{t, m}\right)^{2}}{Q_{t, m}}
$$

where $Q_{t, e}$ and $Q_{t, m}$ are the API fluid interacted acidic amounts at a given time $t$, which were calculated using experimental data and the exponential kinetic model, respectively. The $\chi^{2}$ test is related to the sum of the squares of the differences between the experimental data and theoretically predicted data from a given model. If the calculated data are consistent with the experimental ones, $\chi^{2}$ will have a small numerical value (typically less than 0.01 ). The kinetic parameters, presented in Table I, have an excellent agreement between the experimental and calculated data, which were found using the exponential kinetic model for all kinetic curves evaluated $\left(\chi^{2}\right.$ less than $\left.1.07 \times 10^{-5}\right)$.

The kinetic parameters of API fracturing fluid onto slurry-2 are shown in Table I. In this work, temperature has little influence on the kinetic parameters $k$ and $a$. The values of the kinetic parameter $a$ can also provide information concerning the mechanistic features of the interaction phenomena at the solid/solution interfaces. During the fitting procedure, this parameter has only been considered as an adjustable parameter that may be a nonintegral number. However, in many cases a mechanistic interpretation of this parameter can be proposed, even if its significance in the present case in at most uncertain. Typically, the parameter $a$ has numerical values between 1.0 and 4.0. When 
the reaction occurs on specific sites high values for a are found (2, 3, or higher). Three dimensional reactions result in a values from 3.0 to about 3.5. In last stages of reaction, the interaction may be restricted to one or two dimensions, leading to $a$ values of 1,2, or 2.5-3.0 for surface, edge and point sites in internal sites of the material, respectively. The average values found for a, from 0.432 to 0.566 , suggest that diffusion-controlled processes govern the overall rate of interaction process or are partially involved in it. $^{34-36}$ These arguments lead to acidic diffusion without chemical reaction as the main mechanism occurring at slurry-2/API fluid interface. This finding is in good agreement with the excellent chemical stability of slurry-2, even after long-term contact with acidic API fluid.

\section{CONCLUSIONS}

In this study, a novel oilwell cement slurry was prepared with $\mathrm{A} / \mathrm{F}$ bisphenol-chitosan and it was characterized by ${ }^{29} \mathrm{Si}$ NMR and EPR spectroscopy, before and after contact with an API hot fluid used in routine fracturing procedures in oil and gas industry. For the A/F bisphenol-modified cement slurry, the ${ }^{29} \mathrm{Si}$ NMR spectrum has shown the same peaks observed in the pristine cement/silica slurry. The ${ }^{29} \mathrm{Si}$ NMR spectra of this slurry are more or less the same before and after contact with the acid fracturing fluid, suggesting that this polymer-modified cement slurry is largely unaffected, even after long-term contact with the API hot fracturing fluid.

The main absorption lines of the EPR spectra of the slurries were due to the presence of different $\mathrm{Fe}^{3+}$ ion domains, located at rhombic sites or in distorted tetrahedral and/or octahedral symmetries. After hot fluid contact, the intensities of all EPR lines decreased markedly, due to partial leaching of $\mathrm{Fe}^{3+}$ and $\mathrm{Mn}^{2+}$ from the hardened cement slurry structure. On the other hand, the EPR spectra of the polymer-modified slurry are quite similar before and after hot fluid contact, which underlines the protective effect of the branched polymeric net against the acidic leaching of the main chemical components of cement slurries.

A kinetic order-variable equation was used to calculate kinetic parameters of the interaction of the fracturing fluid onto slurry2. In general, temperature has a little influence on the kinetic parameters $k$ and $a$. The values of the kinetic parameters suggest that diffusion-controlled processes without chemical reactions govern the overall rate of slurry-2/API fluid interaction processes or are partially involved in it.

Most importantly, long-term diffusion of API fluid into slurry-2 was verified without appreciable changes in the structural features of this cement slurry. Therefore, it is clearly evidenced that oil well cement slurry with epoxidized A/F bisphenol-chitosan may be a good option for environmental friendly longterm applications in oil and gas industry.

\section{ACKNOWLEDGMENTS}

The authors would like to acknowledge Schumberger Petroleum Services (Nossa Senhora do Socorro/SE, Brazil) for the continuous technical support to our research group in Brazil and P. Gaveau (Institut Charles Gerhardt, Montpellier, France) for his support during the NMR experiments. E.F.S.V., A.S.M and A.R.C. are indebted with the Brazilian agency $\mathrm{CNPq}$ for financial support (processes 471896/2009-8 and 472314/2011-4) and fellowships.

\section{REFERENCES}

1. Latanision, R. M., Ed. Lessons from the Macondo Well Blowout in the Gulf of Mexico, The Bridge; National Academy of Engineering: Washington, DC, 2012.

2. Hewlett, P. C., Ed. Lea's Chemistry of Cement and Concrete; Elsevier: Burlington, 1998.

3. Taylor, H. F. W. Cement Chemistry, 2nd ed.; Thomas Teldford, 1997.

4. Portier, S.; Vuataz, F.-D.; Nami, P.; Sanjuan, B.; Gerard, A. Geothermics 2009, 38, 349.

5. Dorner, H. W.; Beddoe, R. E. Prognosis of concrete corrosion due to acid attack, 9th International Conference of Building Materials, Brisbane, Australia, 2002.

6. Shi, C.; Stegemann, J. A. Cem. Concr. Res. 2000, 30, 803.

7. Pavlik, V. Cem. Concr. Res. 1994, 24, 551.

8. Pavlik, V. Cem. Concr. Res. 1996, 26, 475.

9. Zivica, V.; Bajza, A. Constr. Build. Mater. 2001, 15, 331.

10. Shirshova, N.; Menner, A.; Funkhouser, G. P.; Bismarck, A. Cem. Concr. Res. 2011, 41, 443.

11. Czarneck, L. Adhesion-A Challenge for Concrete Repair. In concrete repair, rehabilitation and retrofitting II, Alexander, M. G., Ed., Taylor \& Francis: London, 2008.

12. Djouani, F.; Connan, C.; Chehimi, M. M.; Benzarti, K. Surf. Interface Anal. 2008, 40, 146.

13. Chougnet, A.; Audibert, A.; Michel, M. Rheol. Acta 2007, 46, 793.

14. Momayez, A.; Ehsani, M. R.; Ramezanianpour, A. A.; Rajaie, H. Cem. Concr. Res. 2005, 35, 748.

15. Dean, J. M.; Verghese, N. E.; Pham, H. Q., Bates, F. S. Macromolecules 2003, 36, 9267.

16. Cestari, A. R.; Vieira, E. F. S.; Alves, F. J.; Silva, E. C. S.; Andrade, M. A. S., Jr. J. Hazard. Mater. 2012, 213-214, 109.

17. Guibal, E. Separ. Purif. Technol. 2004, 38, 43.

18. Beaudoin, J. J.; Raki, L.; Alizadeh, R. A. Cem. Concr. Compos. 2009, 31, 585.

19. Gopalakrishnan, R.; Govindarajan, D. New J. Glass Ceram. 2011, 1, 119.

20. Brückner, A. Chem. Soc. Rev. 2010, 39, 4673.

21. Cestari, A. R.; Vieira, E. F. S.; de Oliveira, I. A.; Bruns, R. E. J. Hazard. Mater. 2007, 143, 8.

22. Hidalgo, A.; Domingo, C.; Garcia, C.; Petit, S.; Andrade, C.; Alonso, C. J. Mater. Sci. 2008, 43, 3101.

23. Björnström, J.; Martinelli, A.; Matic, A.; Börjesson, L.; Panas, I. Chem. Phys. Lett. 2004, 392, 242.

24. Ershadi, V.; Ebadi, T.; Rabani, A. R.; Ershadi, L.; Soltanian, H. Int. J. Environ. Sci. Dev. 2011, 2, 128.

25. Le Saoût, G.; Lecolier, E.; Rivereau, A.; Zanni, H. Cem. Concr. Res. 2006, 36, 428. 
26. Poulsen, S. L.; Kocaba, V.; Le Saoût, G.; Jakobsen, H. J.; Scrivener, K. L.; Skibsted, J. Solid State Nucl. Magn. Reson. 2009, 36, 32.

27. Dilnesa, B. Z.; Lothenbach, B.; Le Saout, G.; Renaudin, G.; Mesbah, A.; Filinchuk, Y.; Wichser, A.; Wieland, E. Cem. Concr. Res. 2011, 41, 311.

28. Dietzel, M. Geochim. Cosmochim. Acta 2000, 64, 3275.

29. Plank, J.; Zhimin, D.; Keller, H.;van Hössle F.; Seidl, W. Cem. Concr. Res. 2010, 4045.

30. García-Lodeiro, I.; Fernández-Jiménez, A.; Blanco, M. T.; Palomo, A. J. Sol-Gel Sci. Technol. 2008, 45, 63.
31. Balena, S. P.; Messerschmidt, I.; Tomazoni, J. C.; Guimarães, E.; Pereira, B. F.; Ponzoni, F. J.; Blum, W. E. H.; Mangrich, A. S. J. Braz. Chem. Soc. 2011, 22, 1788.

32. Fukamachi, C. R. B.; Wypych, F.; Mangrich, A. S. J. Colloid Interface Sci. 2007, 313, 537.

33. Vieira, E. F. S.; da Costa, L. P.; Cestari, A. R. J. Appl. Polym. Sci. 2010, 118, 857.

34. Ho, Y. S.; McKay, G. Process Biochem. 1999, 34, 451.

35. Cestari, A. R.; Vieira, E. F. S.; Tavares, A. M. G.; Andrade, M. A. S., Jr. J. Colloid Interface Sci. 2010, 343, 162.

36. Cestari, A. R.; Vieira, E. F. S.; Vieira, G. S.; Almeida, L. E. J. Hazard. Mater. 2006, 138, 133. 